\title{
Eksplorasi Fungsi Tindak Tutur Komisif sebagai Konsep Bushido pada Tokoh Samurai dalam Film Rurouni Kenshin
}

\author{
${ }^{1}$ Dian Eka Safitri, ${ }^{2}$ Hamzon Situmorang, ${ }^{3}$ Namsyah Hot Hasibuan \\ University of Sumatera Utara \\ 1dianeka.de91@gmail.com \\ 2hamzonsitumorang@yahoo.com \\ 3namsyah@gmail.com
}

DOI: $10.18196 /$ jjlel.4135

\begin{abstract}
Abstrak
Penelitian ini bertujuan untuk mengetahui fungsi tindak tutur komisif yang dituturkan oleh tokoh samurai dalam film Rurouni Kenshin serta kaitannya dengan konsep bushido. Dalam pengumpulan data digunakan metode simak dengan teknik unduh, lalu dilanjutkan dengan teknik catat. Dalam penganalisisan data, tindak tutur telah dicatat diklasifikasikan berdasarkan fungsi tuturannya dengan menggunakan metode padan beralat penentu mitra tutur. Lalu disesuaikan dengan konsep bushido. Dari hasil penelitian, ditemukan 17 tindak tutur ilokusi komisif pada tokoh samurai dalam film Rurouni Kenshin, dengan fungsi sebagai berikut fungsi berjanji (4 tuturan), fungsi mengancam (8 tuturan), fungsi menolak (1 tuturan), fungsi menawarkan (3 tuturan) dan fungsi menjamin (1 tuturan). Berdasarkan konsep bushido, ditemukan 1 tuturan yang menunjukkan kehormatan (meiyo), 2 tuturan yang menunjukkan kebajikan (jin), 1 tuturan yang menunjukkan ketulusan (gi), 3 tuturan yang menunjukkan keberanian (yuu), 2 tuturan yang menunjukkan kesetiaan (chuugi), 1 tuturan yang menunjukkan kejujuran (makoto), 0 tuturan yang menunjukkan nilai kesopanan (rei) dan 7 tuturan tidak sesuai dengan nilai bushido. Dapat disimpulkan bahwa pada tahun 1868-1878 konsep bushido masih digunakan, meskipun beberapa tindak tutur tidak sesuai dengan konsep bushido disebabkan datangnya era baru.
\end{abstract}

Kata kunci: tindak tutur, ilokusi, komisif, samurai, rurouni kenshin

\footnotetext{
Abstract

(Title: The exploration of Commissive Speech Acts Function of Samurai Characters in Rurouni Kenshin Film: A Pragmatic Study) This research aims to know the functions of commissive speech acts spoken by samurai characters in
} 


\section{VOL. 4, NO. 1 \\ FEBRUARI 2020}

Rurouni Kenshin film and its relation to the concept of bushido. In collecting data, the researchers used the refer method by download technique, continued by note technique. In analyzing data, noted speech acts classified by its functions using the padan method by the determinant of the speech partner, then adapted to the concept of bushido. Based on the result, there were 17 commissive illocutionary speech acts of samurai characters in the Rurouni Kenshin film. The functions found were promising (4 speeches), threatening (8 speeches), refusing (1 speech), offering (3 speeches), guaranteeing (1 speech). Based on the bushido concept, 1 speech of honor value (meiyo), 2 speeches of virtue value (jin), 1 speech of sincerity value (gi), 3 speeches of courage value (yuu), 2 speeches of loyalty value (chuugi), 1 speech of honesty value (makoto), 0 speech of politeness value, and 7 speeches which not following the concept of bushido. In 1868-1878, the bushido concept still used, although some speech acts were not developing the bushido concept caused by the coming of a new era.

Keywords: speech act, illocutionary, commissive, samurai, rurouni kenshin

\section{PENDAHULUAN}

Tindak tutur merupakan bagian penting dalam budaya, yang dengan keberadaannya dapat dimanfaatkan dalam pengenalan identitas suatu masyarakat. Untuk memaknai suatu tindak tutur, dibutuhkan pemerhatian terhadap konteks situasi, budaya serta situasi tuturan dan mitra tutur agar ujaran yang dituturkan dapat dipahami fungsi dan maknanya secara benar oleh lawan bicara. Konteks tuturan berkaitan dengan nilai-nilai moral, kepercayaan pepatah, petuah dan hal-hal yang bersifat mengatur tuturan, sikap dan cara berhubungan dalam masyarakat.

Budaya suatu masyarakat tidak bersifat tetap, karena bisa dipengaruhi oleh budaya asing yang masuk ke dalam masyarakat tertentu hingga lama kelamaan menjadi samar antara budaya asli dan budaya baru yang masuk. Terutama pada era yang sangat maju saat ini, suatu masyarakat maupun negara lebih mudah kehilangan identitasnya. Akan tetapi, tidak semua negara kehilangan identitasnya. Salah satu negara maju yang mampu menjaga budayanya serta menjaga keseimbangan antara kehidupan sosial dan modern adalah Jepang. Jepang merupakan negara yang sangat perlu ditiru dalam hal ini. 
Negara yang kehilangan budaya aslinya dapat berakibat kepunahan, maka bangsa Indonesia juga sebaiknya menjaga identitas budayanya di saat masuknya arus budaya asing ke Indonesia.

Perkembangan budaya Jepang, tidak bisa dipisahkan dari peran samurai yang telah bertindak sebagai kaum elit militer dengan menanamkan konsep pemikiran bushido selama 650 tahun di Jepang. Untuk mengetahui konsep bushido ini, maka dilakukan penelitian terhadap salah satu film sejarah tentang samurai di Jepang yang berjudul Rurouni Kenshin.

Rurouni Kenshin disutradarai oleh Keishi Ohtomo yang 75\% disadur dari kehidupan nyata masyarakat Jepang pada zamannya yaitu dimulai dari tahun 1868 di mana terjadi peristiwa bakumatsu (pemberontakan oleh kaum feodal yang menentang Jepang membuka diri pada kaum asing terutama Eropa) hingga tahun 1878 (10 tahun restorasi Meiji). Pada film ini diceritakan kehidupan seorang samurai pengembara yang telah berhenti membunuh, dan demi penebusan dosanya dia ingin berjuang dalam menciptakan kedamaian di Jepang. Pada film ini terlihat cara samurai mempertahankan pemikirannya melalui tindak tutur yang diujarkannya.

Austin (1962) dalam Chaer dan Agustina (1995) merumuskan adanya tiga jenis tindak tutur, yaitu tindak tutur lokusi, tindak tutur ilokusi, dan tindak tutur perlokusi. Namun dalam penelitian ini yang dibahas adalah salah satu jenis tindak tutur ilokusi, yaitu tindak tutur ilokusi komisif. Tindak tutur ilokusi komisif atau kousokugata (拘束型) yaitu tindak tutur yang membatasi tindakan penutur itu sendiri. Tindak tutur jenis ini dipahami oleh penutur untuk mengikat dirinya terhadap tindakan-tindakan di masa datang, yang mengharuskan si penutur melakukan tindakan yang terdapat di dalam tuturannya (Searle (1969) dalam Yamaoka (2006)). Alasan pemilihan jenis tindak tutur ilokusi ini karena masyarakat Jepang dikenal dengan budaya tanggung jawab, jujur dan menepati janjinya. Sehingga tentunya budaya ini terlihat dari 
VOL. 4, NO. 1

FEBRUARI 2020

tindak tutur masyarakat Jepang tersebut. Hal seperti ini juga terlihat pada karakter seorang samurai.

Sehingga dalam mempelajari karakter samurai Jepang tentu tidak terlepas dari mempelajari fungsi dari tindak tutur yang diucapkan oleh seorang samurai. dalam hal ini, tindak tutur yang akan dibahas adalah tindak tutur ilokusi komisif. Tindak tutur jenis ini mengandung ungkapan ancaman, janji, kontrak, penolakan, sumpah, jaminan dan tawaran. Adapun pemilihan tindak tutur ini untuk mengetahui fungsi ataupun daya tuturan yang dituturkan oleh tokoh samurai dalam film tersebut.

Dalam pengkajian tindak tutur ini, digunakan pendekatan pragmatik, yaitu dengan pengkajian makna satuan bahasa dari tiga sisi, yaitu pengucapan atau penulisan kalimat, acuan kalimat, dan konteks non linguistik. Konteks non linguistik ini berkaitan dengan norma-norma, nilai-nilai, kepercayaan dari budaya suatu masyarakat atau bangsa yang dimaksud. Maka, dalam mengeksplorasi fungsi tindak tutur samurai dalam film tersebut harus diperhatikan kaitannya dengan nilai-nilai pemikiran samurai yang disebut dengan bushido.

Konsep bushido ini dianggap mampu menjamin relevansi lokal, membantu menghindari hilangnya identitas lokal, dan memproteksi ketertarikan lokal dari globalisasi yang berlebihan. Hal ini juga diuraikan oleh Inazo Nitobe dalam bukunya Bushido: Samurai Ethics and the Soul of Japan (2004)

"Bushido is the code of moral principles which the knights were required or instructed to observe. It is a code unuttered and unwritten, possessing all the more the powerful sanction of veritable deed, and of a law written on the fleshly tablets of the heart. It was founded not on the creation of one brain, however able, or on the life of a single personage, however renowned" 
Bushido adalah kode prinsip-prinsip moral yang diminta atau diperintahkan oleh para ksatria untuk dipatuhi. Bushido merupakan kode yang tidak diubah-ubah dan tidak ditulis, namun memiliki semua sanksi yang lebih kuat atas perbuatan yang benar dan sebuah hukum yang tertulis pada tiap unsur pada hati manusia. Itu terbentuk bukan berdasarkan pemikiran satu orang ataupun kehidupan seseorang, akan tetapi dimiliki dan diketahui setiap orang. Nitobe (2015) dalam "Bushido The Soul of Samurai" menjelaskan tujuh nilai bushido, yaitu:

a. Kejujuran (makoto), ajaran paling dasar dalam nilai samurai. Kejujuran melahirkan nilai lain yang disebut dengan giri (nilai tanggung jawab) dalam segala tindakan yang telah diputuskan atau dilakukan.

b. Keberanian (уии), ajaran untuk berani melakukan yang benar meskipun dalam keadaan bahaya, walaupun dapat mempertaruhkan diri sendiri. Nitobe juga menjelaskan bahwa orang yang benar-benar pemberani akan tetap tenang dan menjaga pikirannya agar tetap bersih meskipun dalam keadaan terdesak.

c. Kebajikan (jin), diuraikan sebagai nilai yang lembut dan penyayang bagi seorang samurai yang paling berani. Belas kasih yang diberikan pun harus berdasarkan pada keadilan.

d. Kesopanan (rei), merupakan bentuk penghargaan terhadap kualitas sesuatu terhadap seseorang. Kesopanan menjadi ekspresi penuh keanggunan dari rasa simpati.

e. Ketulusan (gi), merupakan awal dan akhir dari semua tindakan. Dalam menunaikan janjinya, seorang samurai akan bersumpah demi dewa dan pedangnya dengan ketulusan.

f. Kehormatan (meiyo), dimaksudkan jika seorang samurai tidak pernah gagal dalam melaksanakan janjinya maka akan memiliki pengjormatan 
VOL. 4, NO. 1

FEBRUARI 2020

yang tinggi. Namun jika seorang samurai gagal dalam menjalankan tugasnya maka akan merasa malu.

g. Kesetiaan (chuugi), merupakan kunci utama dalam norma penghormatan seorang samurai. Konsep kesetiaan seorang samurai bahwa dalam keadaan apapun bushido tidak pernah goyah dalam mengikuti nilai kesetiaan.

Dengan melihat uraian di atas, dapat diketahui bahwa konsep pemikiran bushido ini sudah lama dan masih dianut oleh masyarakat Jepang hingga saat ini. Meskipun tidak tertulis secara rinci, konsep pemikiran bushido ini tersampaikan dari masa ke masa dan melekat di hati samurai dan masyarakat Jepang. Hal ini tercermin melalui tutur dan sikap masyarakat pengguna konsep pemikiran bushido tersebut. Sebagai contoh berikut merupakan salah satu tindak tutur komisif tokoh samurai dalam film tersebut:

\section{刀を納めるでござる}

Katana wo osameru degozaru

Aku tidak akan menghunus pedangku

Fungsi tuturan di atas adalah fungsi berjanji dari seorang samurai yang bernama Kenshin.

Makna tuturan : Samurai Kenshin berjanji untuk tidak menghunuskan pedang kepada lawan yang tidak menggunakan pedang. Hal ini disebabkan pedang hanya boleh dilawan pedang. Pemikiran ini sesuai dengan konsep bushido bahwa dengan pedang samurai bertahan hidup, dan bila mereka mati sekalipun harus karena bertempur dengan pedang atau petarung pedang lainnya (samurai). Pedang dianggap sebagai ruh bagi para samurai, sehingga harus dijaga dengan baik oleh si pemiliknya sampai akhir kehidupannya,

Pada tindak tutur di atas juga terlihat komitmen seorang samurai bahwa samurai harus berpegang teguh pada janjinya yaitu tidak menggunakan pedang 
untuk melawan alat yang bukan pedang. Dengan adanya komitmen dalam kehidupan samurai Jepang, maka masyarakat Jepang dapat menjaga keutuhan budayanya hingga saat ini.

Karakter masyarakat Jepang yang memegang teguh janji dan komitmennya, membuat masyarakat Jepang memiliki identitas bangsanya sendiri yaitu melindungi budaya asli masyarakat Jepang dari pengaruh masyarakat luar yang masuk ke dalam Negara Jepang. Terutama pada masa itu, terdapat banyak bangsa asing yang masuk ke Jepang demi menyebarkan pengaruh agama, persenjataan, obat-obatan terlarang dan sebagainya.

Dalam penelitian ini permasalahan yang dianalisis adalah fungsi tindak tutur ilokusi komisif yang dituturkan oleh tokoh samurai dalam film Rurouni Kenshin serta kaitannya dengan konsep pemikiran samurai Jepang, yaitu bushido.

\section{METODE PENELITIAN}

Pada penelitian ini digunakan metode simak (menyimak) dan teknik catat dalam pengumpulan datanya. Dikatakan metode simak karena dalam metode ini digunakan cara menyimak dalam memeroleh data (Mahsun, 2005). Pada metode ini teknik yang digunakan adalah menyimak isi tuturan yang terdapat pada film Rurouni Kenshin. Teknik simak dalam hal ini berarti dalam pengumpulan datanya dilakukan penyimakan isi tuturan yang terdapat pada film Rurouni Kenshin kemudian dilanjutkan dengan teknik lanjutan yaitu teknik catat. Pencatatan dilakukan khususnya pada tindak tutur ilokusi komisif yang dituturkan tokoh samurai dalam film Rurouni Kenshin.

Tahap berikutnya adalah penganalisisan data, tindak tutur ilokusi komisif yang telah dicatat, diklasifikasikan berdasarkan fungsi tuturannya tersebut, dipahami maknanya dengan menggunakan metode padan. Metode padan berfungsi menghubungbandingkan satuan bahasa dengan yang berada di luar bahasa. Alat penentu metode ini bukan merupakan bagian dari bahasa yang 
VOL. 4, NO. 1

FEBRUARI 2020

dimaksud (Sudaryanto, 2015). Dalam penelitian ini digunakan alat penentu mitra wicara atau mitra tutur.

Setelah ditentukan berdasarkan situasi tutur yang sedang terjadi, lalu satuan lingual tersebut dikaitkan dengan fungsi dari tindak tutur ilokusi komisif yang diuraikan oleh Searle. Setelah itu, ditentukan maknanya dengan melihat konsep pemikiran (bushido) samurai yang bertindak tutur ilokusi komisif. Setelah diketahui makna dan fungsi dari masing-masing tindak tutur ilokusi komisif pada tokoh samurai dalam film "Rurouni Kenshin" tersebut, lalu dijelaskan fungsi dan makna tuturan tersebut dikaitkan dengan konsep pemikiran (bushido) pada film Rurouni Kenshin tersebut.

\section{HASIL DAN PEMBAHASAN}

Tindak tutur ilokusi komisif adalah jenis tindak tutur yang mengikatkan dirinya terhadap tindakan-tindakan di masa datang. Berikut terdapat 17 tuturan yang memiliki fungsi tindak tutur ilokusi komisif yang ditemukan pada tuturan tokoh samurai dalam film Rurouni Kenshin.

\section{Fungsi Berjanji}

Fungsi ini berarti bahwa si penutur akan melakukan sesuatu hal di masa datang yang akan ditepatinya. Tuturan yang memiliki fungsi mengemukakan janji yang terdapat pada tindak tutur tokoh samurai dalam film Rurouni Kenshin ada 4 (empat) data sebagai berikut:

Tuturan 1:

刀を納めるでござる

Katana wo osameru degozaru

Aku tidak akan menghunus pedangku

Fungsi Tuturan: Menunjukkan bahwa samurai Kenshin memenuhi janjinya sebagai seorang samurai untuk tidak menghunuskan pedang kepada alat selain 
pedang. Hal ini berkaitan dengan kehormatan (meiyo). Bahwa seorang samurai harus menepati janjinya.

Situasi Tutur: Sanosuke Sagara menantang samurai Kenshin untuk mengadu kekuatan mereka. Namun, samurai Kenshin menolak untuk menghunuskan pedangnya karena senjata yang dimiliki Sanosuke Sagara bukanlah pedang. Makna tuturan: Samurai Kenshin berjanji untuk tidak menghunuskan pedang kepada lawan yang tidak menggunakan pedang. Hal ini disebabkan pedang hanya boleh dilawan pedang.

Tuturan 2:

\section{終わらせて見せる}

Owarasete miseru

Aku akan memperlihatkan mengakhirinya

Fungsi Tuturan: Untuk menunjukkan janji samurai Kenshin untuk menyelesaikan pertarungan walau tanpa membunuh. Samurai Kenshin berpegang teguh pada janjinya walaupun dalam keadaan terancam. Hal ini sesuai dengan keberanian (уии) seorang samurai.

Situasi Tutur: Samurai Kenshin bertarung dengan samurai Gein saat mencari Takani Megumi di kediaman Takeda Kanryu. Samurai Gein saat itu menganggap samurai Kenshin tidak akan memenangkan pertarungan dengannya jika menggunakan pedang bermata terbalik. Akan tetapi, samurai Kenshin berusaha membuktikannya di hadapan samurai Gein.

Makna tuturan: Samurai Kenshin berjanji untuk mengakhiri pertarungan dengan samurai Gein walau dengan cara tidak membunuh atau dibunuh.

Tuturan 3:

薰どのを守るたあ 俺は今一度 人斬りに戻る

Kaoru dono wo mamoru taa ore wa ima ichido hitokiri ni modoru

Demi melindungi nona Kaoru, saya akan kembali sekali lagi menjadi Hitokiri 
VOL. 4, NO. 1

FEBRUARI 2020

(119:57)

Fungsi Tuturan: Untuk menunjukkan janji samurai Kenshin tidak akan kembali menjadi seorang hitokiri. Akan tetapi, janji ini akan dilanggarnya, dan dia bisa kehilangan kehormatannya sebagai seorang samurai. Hal ini bertentangan dengan ajaran konsep bushido.

Situasi Tutur: Samurai Kenshin telah melumpuhkan dan menghilangkan ilmu pedang samurai Jin-E. Lalu untuk menghilangkan jutsu milik samurai Jin-E yang ada di tubuh Kaoru, samurai Kenshin berniat untuk membunuh samurai Jin-E. Makna tuturan: Samurai Kenshin berjanji untuk kembali menjadi hitokiri demi menyelamatkan Kaoru agar tidak mati karena jutsu milik samurai Kenshin.

Tuturan 4:

その連なりを絶つのが, この切れない刀の役目でござる

Sono tsuranari wo tatsu no ga, kono kirenai katana no yakume de gozaru Untuk memutus rantai itu, akan ku gunakan pedang ku yang tidak dapat memotong ini

Fungsi Tuturan: Untuk menegaskan janji samurai Kenshin yang ingin memutuskan rantai dendam di kalangan samurai. Hal ini berkaitan dengan nilai ketulusan (gi), di mana samurai bersumpah demi dewa dan pedang dengan ketulusan.

Situasi Tutur: Setelah samurai Jin-E mati dengan cara bunuh diri, samurai Kenshin pulang bersama Kaoru yang sedang pingsan. Lalu samurai Fujita Goro mendatangi samurai Kenshin yang terluka parah karena melawan samurai Jin-E. Samurai Fujita Goro berusaha mengingatkan samurai Kenshin bahwa dia bisa mati jika terus berpegang teguh pada janji tidak membunuhnya.

Makna tuturan: Samurai Kenshin berjanji untuk menghilangkan dendam yang ada akibat pembunuhan.

2. Fungsi Mengancam, berarti 


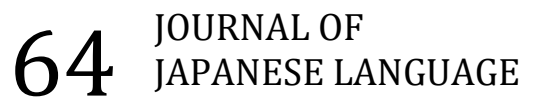 EDUCATION \& LINGUISTICS}

bahwa si penutur mengancam atau memberikan ancaman kepada si mitra tutur jika si mitra tutur tidak melakukan sesuatu yang dikehendaki si penutur ataupun berbuat sesuatu hal yang tidak dikehendaki si penutur. Terdapat 8 tuturan tokoh samurai yang berfungsi mengancam dalam film Rurouni Kenshin.

Tuturan 5:

用心しろ

Youjin shiro

Waspadalah!

Fungsi Tuturan: Untuk mengingatkan Takeda Kanryu bahwa samurai Fujita Goro mengetahui kebenarannya hanya saja masih berbelas kasih memberikan kesempatan pada Takeda Kanryu. Hal ini berkaitan dengan nilai kebajikan (jin) dalam konsep bushido.

Situasi Tutur: Samurai Fujita Goro yang kesal karena Takeda Kanryu menganggap dia bisa terus menutupi perdagangan opiumnya dengan menyuap polisi, mengancam Takeda Kanryu bahwa dia tidak sama seperti polisi umumnya. Dia tidak membutuhkan bukti, karena dia memiliki insting yang tajam sebagai seorang polisi sekaligus seorang samurai.

Makna tuturan: Samurai Fujita Goro mengancam Takeda Kanryu jika sampai terbukti bersalah di mata samurai Fujita Goro.

Tuturan 6:

木刀でしかも女の身で俺に立ち向かうとは

Bokutou de shika mo onna no mi de ore ni tachi mukau to wa

Perempuan dengan pedang kayu berpikir bisa mengalahkanku

Fungsi Tuturan: Untuk menegaskan kepada Kaoru bahwa kemampuan Kaoru tidak sebanding dengan kemampuan samurai Jin-E. Seharusnya samurai Jin-E 
VOL. 4, NO. 1

FEBRUARI 2020

tidak melawan orang yang tidak sebanding dengannya. Hal ini tidak sesuai dengan konsep bushido samurai.

Situasi Tutur: Samurai Jin-E yang telah membunuh banyak orang di kantor polisi pada saat mencari Takani Megumi, diajak bertarung oleh Kaoru. Akan tetapi samurai Jin-E yang sudah haus akan darah tetap akan bertarung dengan Kaoru meskipun Kaoru tidak menggunakan pedang sepertinya. Bahkan dia mengancam akan membunuh Kaoru. Perkataan ini dilanjutkan serangan dari samurai Jin-E kepada Kaoru.

Makna tuturan: Samurai Jin-E mengancam membunuh Kaoru karena berani menantang samurai Jin-E.

Tuturan 7:

下がんなお前、ほら行けよ 行けよ！

Shitagan na omae, hora ike yo ike yo!

Sebelum kau hancur pergilah!

Fungsi Tuturan: Agar samurai Kenshin mengetahui ancaman dari sekelompok samurai liar. Hal ini sesuai dengan konsep kesetiaan (chuugi)yang dimiliki bushido. Karena demi perintah tuan mereka, para samurai liar itu rela melakukan apapun.

Situasi Tutur: Samurai Kenshin yang mengganggu rencana kelompok samurai yang ingin menghancurkan dojo milik Kaoru, akhirnya membuat kelompok tersebut merasa marah. Oleh karena itu, pemimpin kelompok samurai tersebut mengancam samurai Kenshin, jika dia tidak pergi dari hadapan mereka, maka mereka akan menghancurkan samurai Kenshin. Makna tuturan: pemimpin kelompok samurai liar mengancam akan menyakiti samurai Kenshin jika dia berani menghalangi mereka.

Tuturan 8:

己に向いた刃はやがてお前を苦しある事になるぞ 
Onore ni muita ha wa yagate omae wo kurushi aru koto ni naru zo

Balikkan pedangmu, atau kau akan menderita

Fungsi Tuturan: Untuk mengingatkan rasa sakit yang akan diderita samurai Kenshin jika tidak mau membalikkan pedangnya. Hal ini juga bertentangan pada nilai bushido, karena tidak boleh memaksa seorang samurai untuk melanggar janjinya.

Situasi Tutur: Samurai Kenshin dipaksa oleh samurai Fujita Goro untuk membuktikan janji samurai Kenshin bahwa dia tidak akan membunuh lagi. Menurut samurai Fujita Goro tidak mungkin untuk tidak membunuh bagi seorang samurai dalam menegakkan keadilan dan ketertiban. Akan tetapi meskipun dalam pertarungan antara mereka berdua, samurai Kenshin yang telah terluka dan diancam oleh samurai Fujita Goro, tetap saja pada janjinya tidak ingin membalikkan pedangnya untuk menyerang atau bahkan membunuh samurai Fujita Goro.

Makna tuturan: Samurai Fujita Goro mengancam untuk melukai samurai Kenshin lebih parah jika dia tidak membalikkan pedangnya untuk melawan serangan samurai Fujita Goro.

Tuturan 9:

仲間だからな 教えてやる 気をつけろ

Nakama dakarana oshiete yaru ki wo tsukero

Karena kita berteman, ku peringatkan agar kau berhati-hati

Fungsi Tuturan: Untuk memperingatkan Takani Megumi bahwa sesuatu telah ditaruh di sumur air disekitar tempat pelarian Takani Megumi termasuk di kediaman Kaoru. Hal ini berkaitan dengan nilai kebajikan (jin) seorang samurai, yang masih berbelas kasih demi temannya. 
VOL. 4, NO. 1

FEBRUARI 2020

Situasi Tutur: Samurai Gein yang telah meracuni air-air di kediaman wargawarga di sekitar kediaman Kaoru, tidak sengaja bertemu dengan Takani Megumi di kediaman Kaoru. Samurai Gein memperingatkan sekaligus mengancam Takani Megumi, agar dia berhati-hati terhadap serangan orang-orang suruhan Takeda Kanryu.

Makna tuturan: Samurai Gein mengancam akan melakukan apa yang diperintahkan Takeda Kanryu meskipun harus menyakiti Takani Megumi dan orang-orang di sekitar dojo milik Kaoru.

Tuturan 10:

死ね!

Shine!

Matilah kau!

Fungsi Tuturan: Untuk mengancam samurai Kenshin. Hal ini bernilai bushido kesetiaan (chuugi).

Situasi Tutur: Samurai Gein yang bertemu dengan samurai Kenshin saat ingin men yelamatkan Takani Megumi merasa marah karena samurai Kenshin lebih memilih melindungi Kaoru dibandingkan menjadi samurai bayaran Takeda Kanryu. Oleh karena itu, samurai Gein segera ingin membunuh samurai Kenshin. Bentuk bahasa samurai Gein kepada samurai Kenshin yaitu bentuk perintah 'shine' yang berarti 'matilah kau'.

Makna tuturan: Samurai Gein mengancam akan membunuh samurai Kenshin jika terus berusaha melindungi Takani Megumi.

Tuturan 11:

薰どのを巻き込んだ貴さまと

Kaoru dono wo makikonda kisama to

Jika kau melibatkan nona Kaoru maka aku tidak akan sungkan 
Fungsi Tuturan: Untuk mengancam membunuh samurai Jin-E jika membuat nyawa Kaoru terancam. Hal ini tidak sesuai dengan konsep bushido keberanian (уии), karena samurai tidak memiliki ketenangan dalam keadaan terdesak dan bermaksud melanggar janjinya dan akan kehilangan kehormatannya.

Situasi Tutur: Samurai Kenshin yang dipaksa untuk membunuh oleh samurai Jin$E$ jika ingin menyelamatkan Kaoru, akan melanggar janjinya untuk tidak membunuh lagi demi menyelamatkan Kaoru.

Makna tuturan: Samurai Kenshin mengancam akan membunuh samurai Jin-E jika terus berusaha menyakiti Kaoru.

Tuturan 12:

\section{死ね!}

Shine!

Matilah kau!

Fungsi Tuturan: Untuk memperingatkan samurai Jin-E agar bersiap-siap menghadapi kematiannya di tangan samurai Kenshin. Hal ini bertentangan dengan nilai bushido.

Situasi Tutur: Samurai Kenshin yang telah habis kesabaran melihat Kaoru yang disiksa oleh samurai Jin-E akhirnya memutuskan akan membunuh Kaoru. Akan tetapi, Kaoru tetap menghalangi niat samurai Kenshin tersebut, bahkan Kaoru berhasil lepas dari jutsu milik samurai Jin-E.

Makna tuturan: Samurai Kenshin mengancam akan membunuh samurai Jin-E karena terus menyakiti Kaoru dan tidak melepaskan jutsu nya dari Kaoru.

3. Fungsi menolak, berarti bahwa si penutur menolak terhadap hal yang ditawarkan si mitra tutur. Fungsi mengemukakan penolakan yang terdapat pada tindak tutur tokoh samurai dalam film Rurouni Kenshin ada 1 (satu) sebagai berikut:

Tuturan 13: 
お断りするでござるよ

Okotowari suru de gozaru yo

Maafkan saya menolak

Fungsi Tuturan: Untuk menolak tawaran pekerjaan dari Takeda Kanryu. Hal ini berkaitan dengan nilai kejujuran (makoto) samurai. Situasi Tutur: Samurai Kenshin ditawarkan pekerjaan sebagai samurai bayaran Takeda Kanryu oleh Takeda Kanryu dengan gaji setara sepuluh orang samurai. Akan tetapi, samurai Kenshin menolak tawaran tersebut karena Takeda Kanryu adalah orang jahat yang berbuat semena-mena.

Makna tuturan: Samurai Kenshin menolak tawaran Takeda Kanryu untuk menjadi samurai bayarannya.

4. Fungsi Menawarkan, berarti

memberikan tawaran kepada mitra tutur. Fungsi memberikan tawaran yang terdapat pada tindak tutur tokoh samurai dalam film Rurouni Kenshin ada 3 (tiga) sebagai berikut:

Tuturan 14:

いい值をつけてやる

Ii ne wo tsukete yaru

Aku akan memberi harga yang pantas

Fungsi Tuturan: Untuk menawar dojo milik Kaoru. Hal ini bertentangan dengan nilai bushido kesopanan (rei), dan juga ketulusan (gi). Samurai tidak boleh memaksa dan tak tulus dalam berkata atau berbuat sesuatu.

Situasi Tutur: Saat Kaoru sedang membersihkan dojo miliknya di pagi hari, sekelompok samurai liar datang untuk menawar dojo miliknya. Akan tetapi Kaoru menolak hal tersebut, karena dojo tersebut satu-satunya warisan yang dimilikinya. 
Makna tuturan: Pemimpin kelompok samurai liar menawar dojo milik Kaoru dengan harga yang layak.

Tuturan 15:

\section{その剣で自分達を活かしてみるか？}

Sono ken de jibuntachi wo ikashite miru ka?

Lalu pedang di sana itu apakah kau tidak mencoba bertahan hidup menggunakannya?

Fungsi Tuturan: Untuk menawarkan pedang kepada Kaoru agar bisa menyelamatkan dirinya. Hal ini bertentangan dengan nilai ketulusan ( gi), karena samurai tersebut hanya mempermainkan Kaoru.

Situasi Tutur: Saat Kaoru mengatakan bahwa pedang bukan untuk membunuh, kelompok samurai liar tersebut menertawakannya. Lalu mereka menawarkan Kaoru untuk mengambil sebuah pedang untuk bisa menghidupkan dirinya.

Makna tuturan: Pemimpin kelompok samurai liar menawarkan Kaoru sebuah pedang untuk dapat menghidupkan diri Kaoru (hanya sebuah ejekan untuk Kaoru).

Tuturan 16:

方法はニつに 一つ自カで解くか 術者を殺して 剣気を断ち切るか Houhou wa futatsu ni, hitotsu jiryoku de tokuka jyussha wo koroshite kenki wo tachikiru ka.

Hanya ada dua jalan, yang pertama habisi dia atau bunuh pengguna jutsu nya

Fungsi Tuturan: Untuk menawarkan dua pilihan kepada samurai Kenshin. Membunuh Kaoru agar tidak tersiksa, atau membunuh samurai Jin-E sebagai si pemilik jutsu. Hal ini juga bertentangan dengan nilai bushido karena tidak memiliki kebajikan (jin). 
Situasi Tutur: Saat Kaoru dalam keadaan sekarat karena jutsu milik samurai Jin-E. Samurai Jin-E menawarkan dua pilihan kepada samurai Kenshin. di antara kedua pilihan tersebut intinya adalah samurai Kenshin harus kembali membunuh.

Makna tuturan: Samurai Jin-E menawarkan pilihan kepada samurai Kenshin, apakah membunuh dia atau membunuh Kaoru agar Kaoru tidak tersiksa.

5. Fungsi Menjamin, berarti

bahwa si penutur menjamin akan terjadi atau tidak terjadinya sesuatu hal di masa yang akan datang. Fungsi mengemukakan jaminan yang terdapat pada tindak tutur tokoh samurai dalam film Rurouni Kenshin ada 1 (satu) sebagai berikut:

Tuturan 17:

女はな捨て身になると何をするかわからんぞ

Onna wa na sutemi ni naru to nani wo suru ka wakaran zo

Perempuan tidak tahu melakukan apa jika dia ditinggalkan

Fungsi Tuturan: Untuk menjamin bahwa tidak perlu khawatir atas kepergian Takani Megumi. Hal ini sesuai dengan nilai keberanian (уии) seorang samurai yang tetap tenang walaupun dalam keadaan terdesak.

Situasi Tutur: Saat Takani Megumi lari dari kediaman Takeda Kanryu, salah seorang samurai bayarannya menjamin tidak akan terjadi apa-apa pada bisnis Takeda Kanryu, karena Takani Megumi tidak akan berani melaporkan apapun. Makna tuturan: Samurai A menjamin bahwa Takani Megumi tidak akan berbuat apapun untuk melaporkan kegiatan yang dilakukan Takeda Kanryu kepada polisi.

\section{KESIMPULAN}

Dalam penelitian ini ditemukan 17 (tujuh belas) tindak tutur ilokusi komisif pada tokoh samurai dalam film Rurouni Kenshin. Fungsi yang ditemukan adalah fungsi berjanji (4 tuturan), fungsi mengancam (8 tuturan), fungsi 


\section{JOURNAL OF \\ EDUCATION \& \\ LINGUISTICS}

menolak (1 tuturan), fungsi menawarkan (3 tuturan) dan fungsi menjamin (1 tuturan). Di antara 17 tuturan tersebut, ditemukan 1 tuturan yang menunjukkan kehormatan (meiyo), 2 tuturan yang menunjukkan kebajikan (jin), 1 tuturan yang menunjukkan ketulusan (gi), 3 tuturan yang menunjukkan keberanian (уии), 2 tuturan yang menunjukkan kesetiaan (chuugi), 1 tuturan yang menunjukkan kejujuran (makoto), 0 tuturan yang menunjukkan nilai kesopanan (rei) dan 7 tuturan tidak sesuai dengan nilai bushido.

Berdasarkan hasil penelitian dapat disimpulkan bahwa tahun 1868-1878 konsep bushido masih digunakan para samurai, meskipun konsep bushido mengalami perubahan. Hal ini juga terlihat pada artikel Suliyati, T (2013) yang menjelaskan bushido pada masyarakat Jepang: masa lalu dan masa kini, bahwa nilai budaya masyarakat Jepang mempengaruhi cara pikir mereka dari masa lalu hingga masa sekarang. Mereka menyadari bahwa untuk memerangi dominasi bangsa barat tidak hanya melalui senjata saja, melainkan juga dengan semangat bushido.

\section{REFERENSI}

Austin, John L. 1962. How to do things with words. Oxford: Oxford University Press.

Chaer, Abdul dan Leoni Agustina. 1995. Sosiolinguistik: Suatu pengantar. Jakarta: Rineka Cipta.

Mahsun, M.S. 2005. Metode penelitian bahasa: tahapan strategi, Metode dan Tekniknya. Jakarta: Raja Grafindo Persada.

Nitobe. 2004. Bushido: Samurai ethics and the soul of japan. New York: Dover Publication Inc.

Nitobe. 2015. Bushido: The soul of samurai: Jalan kebijaksanaan kesatria jepang. Jakarta: Daras Book. 
VOL. 4 , NO. 1

FEBRUARI 2020

Searle, John.R. 1969. Speech act: An essay on the philosophy of language. New York: Cambridge University Press.

Sudaryanto. 2015. Metode dan aneka teknik analisis bahasa: Pengantar aneka teknik analisis bahasa. Yogyakarta: Sanata Dharma University Press.

Suliyati, Titiek. 2013. Bushido pada masyarakat jepang: Masa lalu dan masa kini [pdf]. Tersedia. www.ejournal.undip.ac.id. Izumi: Jurnal Bahasa, Sastra dan Budaya Jepang. Vol.I (I). [27 Desember 2013].

Yamaoka, Masaki. 2006. Hatsuwakinou to hatsuwanaikoui. [pdf]. Tersedia.

(www.libir.soka.ac.jp/dspace/.../1/KJ00004860466). International Journal of Pragmatics. (16). 29-45 [20 September 2019].

www.id.m.wikipedia.org 